\title{
Endoscopic ultrasound-guided choledochoduodenostomy and duodenal stenting for combined malignant biliary and duodenal obstruction
}

A 64-year-old man with metastatic cecal adenocarcinoma on palliative chemotherapy presented with both cholangitis and persistent vomiting. Computed tomography demonstrated a dilated common bile duct and gastric outlet obstruction from a malignant stricture at the second part of the duodenum (D2) involving the papilla ( $\triangleright$ Fig. 1 ). A diagnosis of type 2 combined malignant biliary and duodenal obstruction (CMBDO) was made.

Percutaneous biliary drainage was not suitable because of borderline intrahepatic biliary dilatation and patient refusal. The advanced malignancy and ongoing cholangitis precluded surgery. The endoscopic approach was challenging in this case because tumor infiltration of the papilla was causing obstruction and thus prevented conventional endoscopic retrograde cholangiopancreatography (ERCP), and placement of a biliary stent would be difficult following deployment of a duodenal stent. We therefore performed endoscopic ultrasound (EUS)guided choledochoduodenostomy (CDS) using the HOT AXIOS stent $(10 \times 10 \mathrm{~mm}$; Boston Scientific, Marlborough, Massachusetts, USA) followed by subsequent stenting of the duodenal obstruction using a WallFlex metal stent $(22 \times 90 \mathrm{~mm}$; Boston Scientific) ( $>$ Fig. 2, \ Video 1).

We highlight the use of the lumen-apposing HOT AXIOS stent to prevent stent migration and bile leak compared with conventional covered biliary metal stents. The enhanced electrocautery delivery system facilitates direct puncture during stent insertion. Without this delivery device, serial dilatation is required during stent insertion, which risks bile leakage [1]. The flanges with lumen-apposing forces also help to prevent bile leak. As CMBDO could lead to cholangitis and recurrent vomiting, palliative options are essential for patient comfort. Treatment options of CMBDO depend on the location and sequence of obstruction
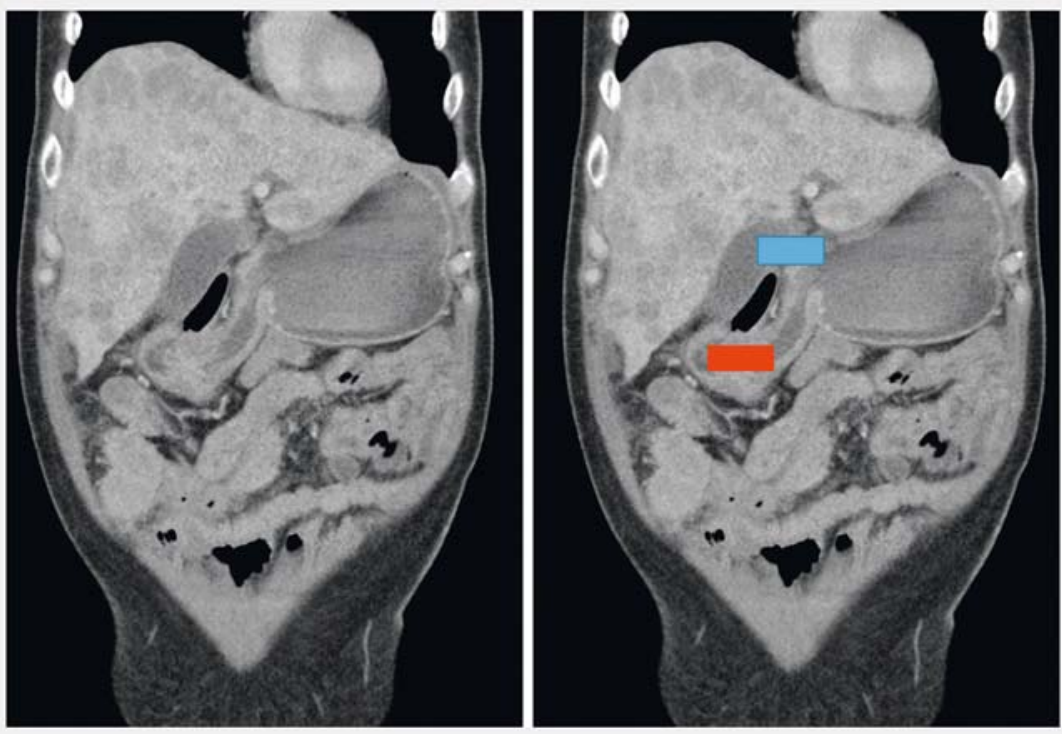

- Fig. 1 Computed tomography of the abdomen and pelvis demonstrated a dilated common bile duct resulting from malignant biliary obstruction involving the ampulla, and gastric outlet obstruction secondary to duodenal obstruction. The proposed locations of the choledochoduodenostomy stent (blue) and the duodenal stent (red) are shown.
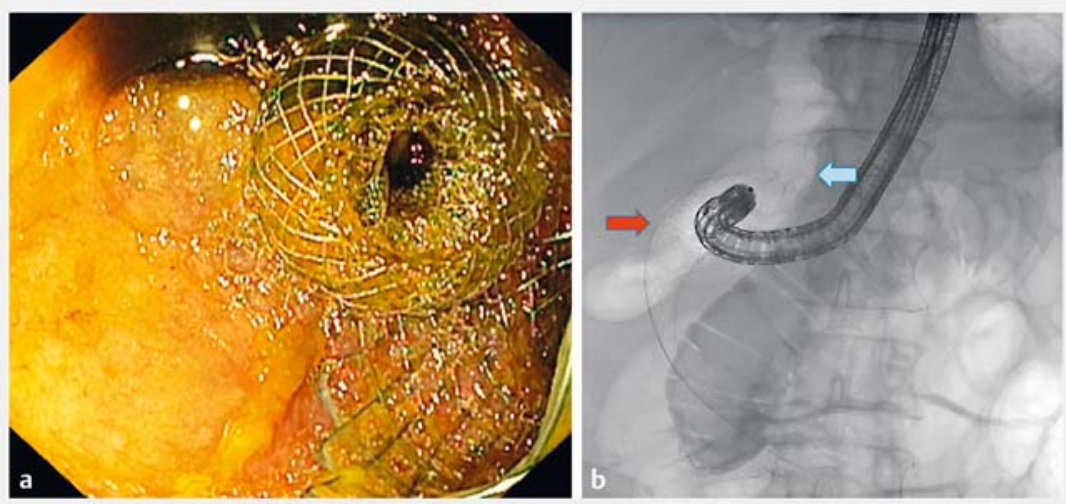

- Fig. 2 Stent placement. a Endoscopic view of the stents. b Fluoroscopic view, showing final placement of the choledochoduodenostomy stent (blue arrow) and the duodenal stent (red arrow).

[2]. EUS-guided CDS using the HOT Endoscopy_UCTN_Code_TTT_1AS_2AD 


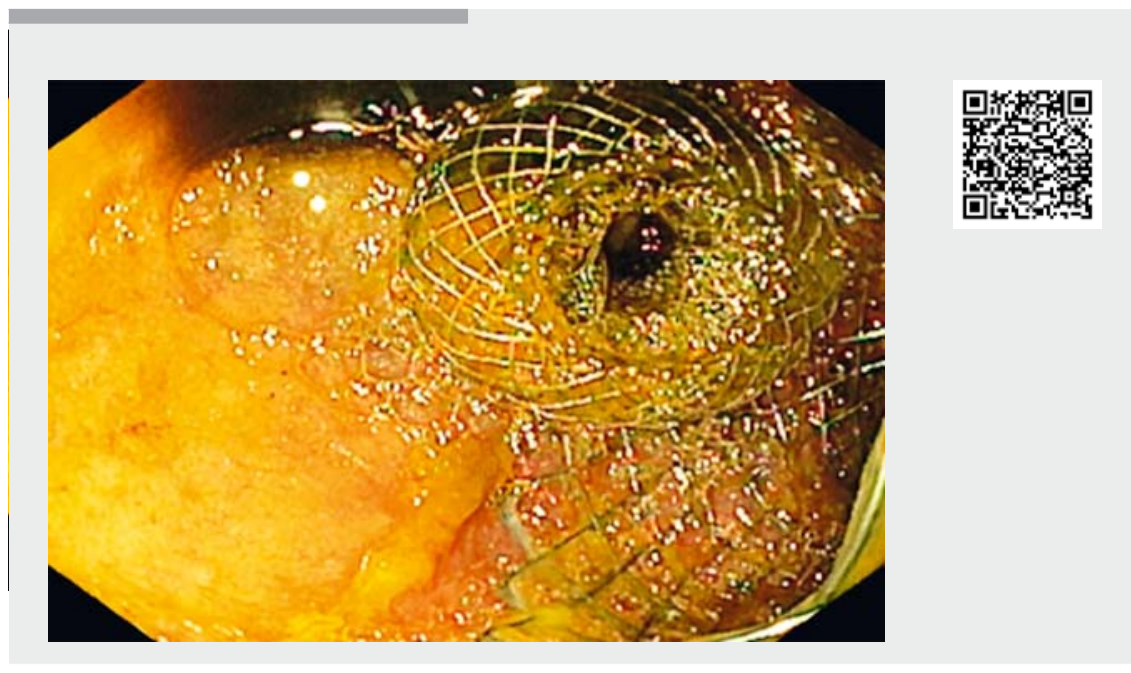

$\checkmark$ Video 1 Endoscopic ultrasound-guided choledochoduodenostomy followed by duodenal stenting in type 2 combined malignant biliary and duodenal obstruction.

\section{Competing interests}

Dr Damien Meng Yew Tan has received consultation and lecture fees from Boston Scientific in the past 3 years.

Dr Christopher Khor has received lecture fees from Boston Scientific in the past 3 years. Dr Yu Jun Wong has no conflict of interest. Dr Jonathan Guo Xiang Teh has no conflict of interest.

The authors

Yu Jun Wong', Jonathan Guo Xiang Teh², Christopher Khor ${ }^{3}$, Damien Meng Yew Tan ${ }^{3}$

1 Department of Gastroenterology and Hepatology, Changi General Hospital, Singapore

2 Department of Internal Medicine, Sengkang General Hospital, Singapore

3 Department of Gastroenterology and Hepatology, Singapore General Hospital, Singapore
Bibliography

DOI https://doi.org/10.1055/a-0929-4927

Published online: 24.7.2019

Endoscopy 2019; 51: E394-E395

(c) Georg Thieme Verlag KG

Stuttgart · New York

ISSN 0013-726X

\section{ENDOSCOPY E-VIDEOS}

https:/|eref.thieme.de/e-videos

回局 Endoscopy E-Videos is a free access online section, reporting 向裙 on interesting cases and new techniques in gastroenterological endoscopy. All papers include a high quality video and all contributions are freely accessible online.

This section has its own submission website at https://mc.manuscriptcentral.com/e-videos
Damien Meng Yew Tan, MD

Department of Gastroenterology and Hepatology, Singapore General Hospital, Outram Road, Singapore 169608

Damien.tan.m.y@singhealth.com.sg

\section{References}

[1] Kawakubo K, Isayama H, Nakai Y et al. Multicenter retrospective study of endoscopic ultrasound-guided biliary drainage for malignant biliary obstruction in Japan. J Hepatobiliary Pancreat Sci 2014; 21: $328-334$

[2] Nakai Y, Hamada T, Koike K et al. Endoscopic management of combined malignant biliary and gastric outlet obstruction. Dig Endosc 2017; $29: 16-25$ 